(1)

CrossMark

\title{
COPD beyond proximal bronchial obstruction: phenotyping and related tools at the bedside
}

\author{
Thibaut Capron ${ }^{1}$, Arnaud Bourdin², Thierry Perez ${ }^{3}$ and Pascal Chanez ${ }^{1,4}$
}

Affiliations: ${ }^{1}$ Clinique des Bronches, Allergies et Sommeil, Hôpital Nord, Assistance Publique des Hôpitaux de Marseille, Aix Marseille Université, Marseille, France. ${ }^{2}$ Université de Montpellier, PhyMedExp, INSERM, CNRS, CHU de Montpellier, Dept of Respiratory Diseases, Montpellier, France. ${ }^{3}$ Dept of Respiratory Diseases, CHU Lille, Center for Infection and Immunity of Lille, INSERM U1019 - CNRS UMR 8204, Université Lille Nord de France, Lille, France. ${ }^{4}$ Aix Marseille Université, INSERM, INRA, CV2N, Marseille, France.

Correspondence: Pascal Chanez, INSERM, INRA, C2VN, Université Aix-Marseille, Clinique des Bronches, Allergie et Sommeil, APHM-Hôpital Nord, Chemin des Bourrely, 13015 Marseille, France. E-mail: pascal. chanezQuniv-amu.fr

@ERSpublications

COPD bronchial obstruction poorly reflects respiratory disability; this review addresses pathways for pathogenesis beyond proximal obstruction through small airways imaging and function, inflammation processes and pulmonary vascular involvement. bit.ly/30JlKVi

Cite this article as: Capron T, Bourdin A, Perez T, et al. COPD beyond proximal bronchial obstruction: phenotyping and related tools at the bedside. Eur Respir Rev 2019; 28: 190010 [https://doi.org/10.1183/ 16000617.0010-2019].

ABSTRACT Chronic obstructive pulmonary disease (COPD) is characterised by nonreversible proximal bronchial obstruction leading to major respiratory disability. However, patient phenotypes better capture the heterogeneously reported complaints and symptoms of COPD. Recent studies provided evidence that classical bronchial obstruction does not properly reflect respiratory disability, and symptoms now form the new paradigm for assessment of disease severity and guidance of therapeutic strategies. The aim of this review was to explore pathways addressing COPD pathogenesis beyond proximal bronchial obstruction and to highlight innovative and promising tools for phenotyping and bedside assessment.

Distal small airways imaging allows quantitative characterisation of emphysema and functional air trapping. Micro-computed tomography and parametric response mapping suggest small airways disease precedes emphysema destruction. Small airways can be assessed functionally using nitrogen washout, probing ventilation at conductive or acinar levels, and forced oscillation technique. These tests may better correlate with respiratory symptoms and may well capture bronchodilation effects beyond proximal obstruction.

Knowledge of inflammation-based processes has not provided well-identified targets so far, and eosinophils probably play a minor role. Adaptative immunity or specific small airways secretory protein may provide new therapeutic targets. Pulmonary vasculature is involved in emphysema through capillary loss, microvascular lesions or hypoxia-induced remodelling, thereby impacting respiratory disability.

\section{Introduction}

Chronic obstructive pulmonary disease (COPD) is a highly prevalent airway disease, most often triggered by cigarette smoke exposure [1]. In addition, it has systemic manifestations and is an important cause of respiratory disability [2].

Based on the Global Initiative for Chronic Obstructive Lung Disease (GOLD) classification, the classic definition is functional, with a bronchial obstruction evidenced by a forced expiratory volume in $1 \mathrm{~s}$

Received: Feb 092019 | Accepted after revision: May 042019

Provenance: Submitted article, peer reviewed.

Copyright $\odot$ ERS 2019. This article is open access and distributed under the terms of the Creative Commons Attribution Non-Commercial Licence 4.0. 
$\left(\mathrm{FEV}_{1}\right)$ /forced vital capacity $(\mathrm{FVC})$ ratio $<0.7$ or below the lower limit of normal (LLN) and which is not fully reversible with bronchodilation [3]. This bronchial obstruction is the cornerstone of COPD, leading to gas trapping and hyperinflation, which limit lung expansion during breathing.

Historically, different patients presented common COPD clinical symptoms, and early phenotypes were defined: the chronic bronchitis on the one hand and the emphysematous presentation on the other hand. Since then, bronchial obstruction has explained pathogenesis in chronic bronchitis, but is not completely satisfactory in patients with a predominant emphysematous phenotype.

Indeed, COPD is a heterogeneous disease and patient phenotypes have to be more precisely identified in order to develop personalised treatments. This rationale has already brought successful therapeutic developments, which now form the current standards [4]. Inhaled corticosteroids associated with long-acting $\beta$-agonists are recommended in the severe frequent exacerbator phenotype, in balance with the risk of pneumonia. Phosphodiesterase- 4 inhibitors (roflumilast) are indicated in the chronic bronchitis phenotype, with at least severe COPD and history of exacerbations. $\alpha_{1}$-antitrypsin augmentation therapy in deficient patients slows down progression of the disease. Emphysematous hyperinflated patients may benefit from surgical or bronchoscopic lung volume reduction after accurate evaluation.

Recent reports in the ECLIPSE (Evaluation of COPD Longitudinally to Identify Predictive Surrogate Endpoints) cohort, comprising COPD patients, smokers with normal lung function and nonsmokers, demonstrated that the degree of airflow limitation does not capture well all aspects of the disease. Notably, comorbidities were more prevalent in COPD patients, irrespective of GOLD stage. Furthermore, permanent airflow impairment was poorly related to important respiratory outcomes such as breathlessness, exercise capacity or exacerbation rate. In contrast, some patients with severe airflow obstruction did not complain of any symptoms [5]. Other studies demonstrated a wide distribution of the COPD assessment test, a score representing disease impact on patient's life, with respect to GOLD stage [6]. Even the time course of bronchial obstruction is variable, with a different FEV1 decline within GOLD stages [7].

Some of these COPD patients or smokers have partially altered or no airflow obstruction. Smokers with FEV1 alterations but no airflow limitation (normal FEV1/FVC ratio) were found to have a wide range of functional limitation, imaging abnormalities and clinical symptoms [8]. More precisely, these preserved ratio impaired spirometry (PRISm) patients were found to represent $12 \%$ of people in a large North-American cohort (COPDgene cohort). They have specific symptoms and morphological features such as emphysema, reduced total lung capacity or increased bronchial wall thickness with respect to control subjects [9]. Similarly, patients with normal FEV1, or FEV1/FVC ratio $<0.7$ but above the LLN had significant COPD-like alterations in terms of chest computed tomography (CT) findings and symptoms [10].

This suggests that the aforementioned abnormalities are the real source of respiratory COPD-like disability. In a population of nonobstructive patients with emphysema, a significant proportion had alterations of quality of life, diffusing capacity and oxygen saturation at exercise and more exacerbations [11]. Another study confirmed that smokers with preserved spirometry have significant respiratory symptoms, quantitative CT-compatible damage and exacerbations of the disease [12]. Other smokers without airflow obstruction, termed GOLD 0, were found to have significant lung CT abnormalities or functional impairment [13].

As a result, bronchial obstruction alone as defined by simple spirometric criteria does not capture the essence of COPD, as illustrated in figure 1. Accordingly, recent modification of COPD severity assessment has discarded the airflow obstruction level as the main qualifying parameter [4] and replaced patients' symptoms at the centre of therapy strategies. Moreover, therapeutics have mainly addressed the bronchial component so far, without succeeding in interfering with natural history of the disease.

In this review, we describe different pathways addressing COPD pathogenesis beyond bronchial obstruction. The aim was to review innovative and promising tools that could improve knowledge on the disease or bring new therapeutics in the future.

We first describe the involvement of small airways, which is a well-known and early feature of COPD. Specifically, we emphasise recent imaging developments in this field and progress in lung functional assessment. Secondly, we present research advances on inflammation-based processes and their consequences. The third section exposes pulmonary vascular component as an independent expression of the disease.

\section{Small airways involvement}

Small airways are classically defined as those having an inner diameter $<2 \mathrm{~mm}$ and without cartilage [14]. In normal lungs, they do not participate in airflow limitation and form the so-called "silent zone" [15]. 


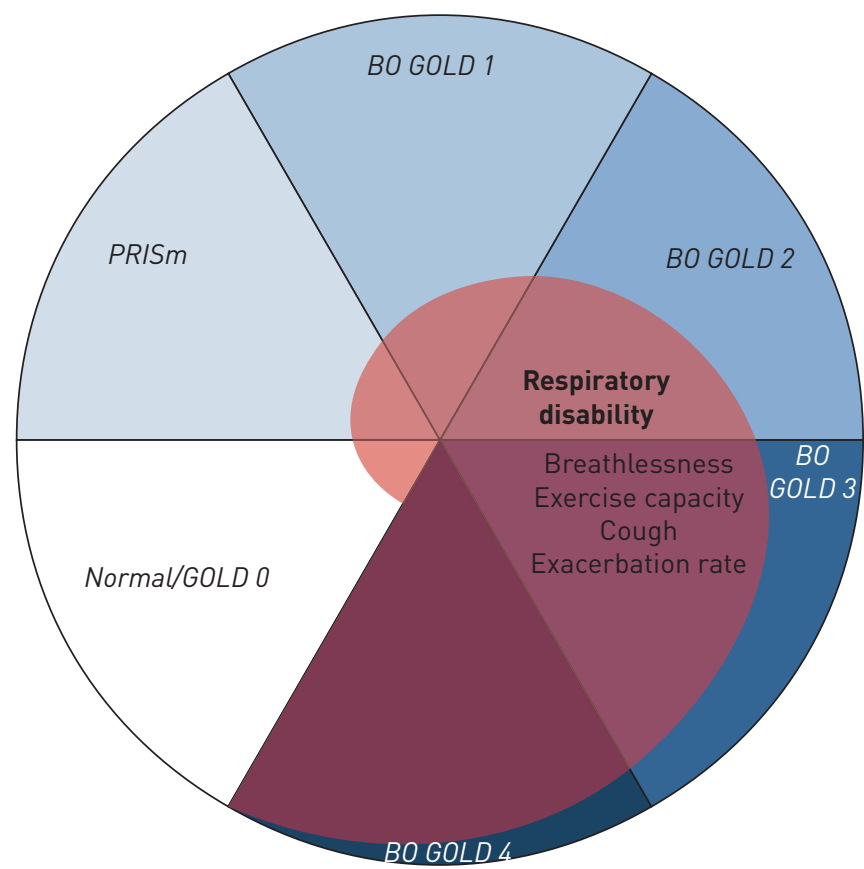

FIGURE 1 Schematic view of chronic obstructive pulmonary disease (COPD) heterogeneity. Mutually exclusive spirometric definitions capture only a part of respiratory disability continuum. BO: bronchial obstruction, as defined by the Global Initiative for Chronic Obstructive Lung Disease (GOLD); PRISm: preserved ratio impaired spirometry.

However, they have been shown to represent the major contribution to airflow limitation in chronic airway disease $[16,17]$.

In healthy subjects, small airways are the site of a laminar flow, the intensity of which varies inversely to the fourth power of airway diameter. As a result, a slight decrease in bronchus radius is very likely to be the main trigger for an increase in airflow limitation. Such behaviour may arise from three main phenomena [18].

First, intraluminal obstruction can occur due to epithelial metaplasia, mucus, microbes, cellular-inflammatory exudates, exogenous particles or deposition of substance (such as in alveolar lipoproteinosis).

Second, increased wall thickness may be caused by oedema, fibrosis, calcifications, increased vascularity, inflammatory infiltration and/or granulomas, but also enlarged smooth muscle and/or increased smooth muscle tone or intraparietal deposition such as amyloid substance.

Finally, airway distortion or narrowing is a result of alveolar attachment loss. This could be seen as a consequence of the decreased lung elastic recoil leading to premature airway closure [19]. Interestingly, this mechanism is related to a parenchymal disease.

There are thus two distinct mechanisms for airflow limitation: a parenchymal component due to loss of alveolar attachment on the one hand and a bronchiolar component on the other hand, resulting from luminal obstruction or airway wall thickening. This is supported by CT studies, suggesting that small conducting airways are predominant in airflow limitation mostly when emphysema is absent, whereas loss of alveolar attachment is important when emphysema is present [20].

\section{Imaging small airways}

Recent advances in CT-based imaging of the lungs have brought great insight in the nature of small airways disease.

CT is the most widely used imaging modality to assess morphological pulmonary disease in COPD. Different types of abnormalities can be addressed [21], as follows.

Emphysema is classically assessed by measuring areas of low attenuation below a threshold of -950 Hounsfield units. It can also be identified through distorted or narrowed vasculature, as observed in maximum intensity projection reconstructions. Visual clinician assessment and quantitative automated 
detection are complementary tools. CT exams at a fraction of the standard dose bring equivalent information.

Airway disease assessment is based on three-dimensional determination of wall thickness and intraluminal area. Automated detection is not satisfying and visual assessment remains the standard.

Airways with diameter $<2 \mathrm{~mm}$ fall below CT resolution. The parametric response map (PRM) is a tool based on volumetric inspiratory and expiratory CT scans that give functional information on small airways and air trapping.

In addition, pulmonary vasculature can be assessed: CT perfusion imaging shows qualitative heterogeneity in smokers and emphysematous patients. Low-diameter pulmonary vessels can be assessed quantitatively with CT image reconstruction processes, without a need for contrast agent [22]. Using this technique, pulmonary blood vessels detectable on CT having cross-sectional area (CSA) $<5 \mathrm{~mm}^{2}$ can be identified (see section on pulmonary vascularisation).

A summary of the main imaging techniques available at bedside is provided in table 1.

Such quantitative CT measurements have been well correlated with variables of interest in COPD. FEV 1 inversely correlated with emphysema and air trapping obtained on chest CT [23]. CT-metrics of emphysema was related to important clinical outcomes, such as BODE (body mass index, airflow obstruction, dyspnoea, exercise capacity) index or quality of life in COPD [24]. Airway wall thickness in combination with emphysema and air trapping were found to be good predictors of COPD [25]. HAN et al. [26] tested an association between COPD exacerbation rate and quantitative CT measurement of emphysema and wall thickness. Adjusted on lung function, the study showed that a 1-mm increase in bronchial wall thickness resulted in a 1.84 -fold increase in exacerbation rate.

Quantitative CT appears to be a reliable tool to identify various abnormalities in COPD that can be used to identify patient's phenotypes or emphysema subtypes [27, 28].

In order to overcome CT resolution limit, micro-CT has been developed to specifically assess small airways in surgically obtained lung tissue samples. Indeed, increased peripheral resistance in chronic airway disease is usually attributed to lumen narrowing as the airflow varies inversely with the fourth power of diameter. In addition, $\sim 90 \%$ of bronchiolar airways need to be removed in order to explain the resistance increase commonly observed in COPD patients. The seminal work of HoGg et al. [29] questioned the relationship between small airway obstruction and emphysematous destruction in COPD. CT was used in ex vivo lungs to determine the number of small airways and micro-CT to assess bronchioles and terminal bronchioles reduction in emphysema. It was found that both narrowing and airways number reduction contribute to FEV1 limitation. Moreover, this study showed that loss of terminal bronchioles precedes the onset of emphysematous destruction [30]. These results suggest that the process begins at very early stage of the disease, raising interest in potential specific therapeutic addressing this issue.

More recently, micro-CT was used to seek structural differences between panlobular and centrilobular emphysema. The disease was more severe in centrilobular emphysema regarding wall thickening and lumen narrowing [31]. It should be noted that this technique relies on ex vivo tissue characterisation, thereby limiting clinical usefulness.

Another recent progress in CT imaging in COPD is the development of PRM [32]. It involves inspiratory and expiratory CT scans with thresholding, which allows the extraction of the extent of emphysema (PRMemph) or the extent of air trapping, called functional small airway disease (PRMfSAD). In the original

TABLE 1 Summary of the main imaging techniques available at bedside for assessment of chronic obstructive pulmonary disease

\begin{tabular}{|c|c|c|}
\hline Target & Principle & Main features \\
\hline Emphysema extent & CT signal thresholding $(-950 \mathrm{HU})$ & Quantitative, possibly automated \\
\hline Airways & CT visual assessment of wall thickness/intraluminal area & Associated with exacerbation rate \\
\hline \multirow{2}{*}{ Small airways } & Emphysema (PRMemph) & Emphysema associated with lower DLco \\
\hline & Air trapping (PRMfSAD) & \\
\hline Vasculature & CT image reconstruction & Quantitative low-diameter vessels proportion (CSA $<5 \mathrm{~mm}^{2}$ ) \\
\hline
\end{tabular}


work, PRM technique showed regional extent of small airways disease and emphysema and supported the concept of functional small airways disease preceding emphysema. Further work using PRM highlighted the role of each component in FEV1 decline [33]. In participants without airflow obstruction, PRMfSAD was associated with FEV1 decline, but not PRMemph. For these patients, functional small airways disease would thus be the main cause of FEV1 decline, but not emphysema. In participants presenting GOLD-defined obstruction, both components were associated with FEV1 decline. Consistently, the specific contribution of emphysema increased with increasing GOLD stage. As a result, functional small airways disease appears to be the major contributor of FEV1 decline in COPD patients. Another recent study found a strong correlation between PRM and COPD disease and severity [34]. Consistently, the functional small airway disease component correlated specifically with increased residual volume and the emphysema component with lowered carbon monoxide diffusion.

Functional assessment of small airways

Pulmonary function testing is a major tool for COPD assessment as spirometry has been used in clinical routine for decades. With recent progress on the role of small airways in chronic airway disease, lung function testing specifically addressed to small airways has regained significant interest.

Among these tests, the most popular so far has been the forced expiratory flow at $25-75 \%$ of FVC (FEF2575\%) [35]. However, this marker is difficult to interpret as it depends on total lung capacity (TLC) and does not add clinical value with respect to $\mathrm{FEV}_{1}$ or FEV1/FVC ratio [36].

Development of airflow obstruction leads to premature airway closing and thus nonuniform distribution of ventilation in the lungs [37]. Specific tests have been derived to assess ventilation heterogeneity as an early marker of small airway disease in COPD. The nitrogen washout technique consists of expelling nitrogen gas contained in the pulmonary alveoli by breathing pure oxygen. The expired nitrogen concentration is measured and two parameters can be extracted: the slope of phase III, which reflects the alveolar washout, and the closing volume. Single-breath nitrogen washout (SBW) tests evenness of ventilation and was related to small airways disease in nonobstructive smokers [38].

However, SBW probes the whole airway tree. In order to overcome this issue, multiple-breath nitrogen washout was proposed by VERBANCK et al. [39]. In this setting, phase III slope first reflects heterogeneity at acinar level (Sacin) and with progressive washouts it becomes sensitive to small conducting airways (Scond). This method could detect ventilation heterogeneity at conductive and acinar levels in mild smokers with normal spirometry [40]. In addition, Scond is conceptually linked to airway calibre (FEV 1 and airway resistance) and Sacin to diffusing capacity of the lung for carbon monoxide (DLCO), suggesting a potential separate analysis of airway and parenchyma destruction [41]. Indeed, the conductive airway component Scond was shown to be reversible after smoking cessation, in contrast with the acinar component [40].

The forced oscillation technique (FOT) involves applying periodic pressure variations in order to obtain airways impedance to flow. It is composed of a reactance component, reflecting capacitive and inertive properties, and a resistance component. Low-frequency oscillations are better transmitted to distal airways and are considered as a probe for small airways [42]. In patients with airflow obstruction, the resistance was found to be particularly increased at low frequencies and decreased at high frequencies [43]. Furthermore, it showed a good discriminative power between asthma, chronic bronchitis and emphysema [44]. Within-breath reactance was showed to provide an accurate, reliable and effort-independent technique to detect expiratory flow limitation in COPD [45]. More recently, FOT showed significantly altered parameters in subjects with COPD, smokers without COPD and nonsmokers [46] and potential to detect symptomatic COPD earlier than spirometry [47].

Table 2 summarises the most widely available pulmonary function testing methods for assessing small airways.

Although these techniques are not new, they have recently become more widely accessible and questions have risen about their functional relevance in COPD. Several studies have brought external validity to FOT and SBW as markers of small airway disease.

For instance, spirometric airflow obstruction was found to be predicted independently by small airways function as measured by FOT, closing volume (measured with SBW) and emphysema extent obtained from CT [48].

Physiological studies found that the degree of ventilation heterogeneity as measured with nitrogen SBW was independently associated with spirometric FVC, FOT and CT emphysema [49]. This result supports the concept that air trapping in COPD leads to ventilation heterogeneity. 


\begin{tabular}{|c|c|c|}
\hline Technique & Principle & Comment \\
\hline FEF $25-75 \%$ & $\begin{array}{l}\text { Spirometric flow interval at } 25-75 \% \text { of } \\
\text { FVC }\end{array}$ & $\begin{array}{l}\text { No added clinical value from other } \\
\text { spirometric indices }\end{array}$ \\
\hline Nitrogen washout & $\begin{array}{l}\text { Nitrogen washout in pulmonary alveoli } \\
\text { reflecting ventilation heterogeneity }\end{array}$ & $\begin{array}{l}\text { SBW relates to SAD } \\
\text { MBW detects heterogeneity at conductive } \\
\text { and acinar levels }\end{array}$ \\
\hline $\begin{array}{l}\text { Forced oscillation } \\
\text { technique }\end{array}$ & $\begin{array}{l}\text { Periodic pressure variations to } \\
\text { measure airways impedance to flow }\end{array}$ & $\begin{array}{l}\text { Low-frequency component probes small } \\
\text { airways } \\
\text { Early sensitive and effort-independent tool } \\
\text { for detection of flow limitation } \\
\text { Specific sensitivity to bronchodilation }\end{array}$ \\
\hline
\end{tabular}

FEF25-75\%: forced expiratory flow at $25-75 \%$ of forced vital capacity (FVC); SBW: single-breath washout; SAD: small airways disease; MBW: multiple-breath washout.

In addition, the clinical impact of spirometric markers beyond historical FEV1 in COPD has been studied. Variation in inspiratory capacity after treatment was found to have better correlation with dyspnoea improvement than FEV1 variation [50]. This supports the idea that dyspnoea is mostly due to hyperinflation hampering inspiratory capacity.

It is also sustained by exercise dyspnoea limitation which occurs when inspiratory reserve volume reaches a specific threshold in COPD patients [51].

New spirometric indices are trying to capture small airways obstruction where FEV 1 failed in mild COPD patients. Current and ex-smokers with normal classic spirometry, but FEV3/FEV6 (forced expiratory volume at 3 and $6 \mathrm{~s}$ ) ratio below LLN were identified as having small airway disease determined by quantitative CT, impaired physical function and quality of life [52]. Such indices have the great advantage of being broadly accessible.

Another study in stage 0 COPD patients reported that small airways disturbance may be detected using FOT and spirometric FEF values as compared to a healthy group [53].

BовсK et al. [54] investigated the association between SBW results and clinical outcomes in COPD. Ventilation heterogeneity was increased in COPD compared with normal subjects. Phase III slope was correlated to classic function indices (FEV1, residual volume/TLC, DLCO) and respiratory symptoms. Results were independent of FEV1 level. These results suggest that SBW is a valuable tool for qualifying COPD.

YAMAGAMI et al. [55] found significant differences in respiratory impedance measured with FOT between COPD exacerbators and nonexacerbators [55].

Regarding response to bronchodilator treatment, results are dissociated. Bronchodilation bitherapy was linked to improvements in small airway function measured by FOT despite unchanged FEV1. However, there was no significant change in ventilation heterogeneity [56]. Another study reported that FOT and inspiratory capacity were significantly improved after bronchodilator treatment [57]. Thus, FOT may be a useful clinical marker of small airway response to treatment in COPD. In addition, it seems that combination of functional tests may capture the responsive (FOT, inspiratory capacity) as well as the nonreversible (ventilation heterogeneity, FEV1) aspects of the classic bronchodilator therapy used in COPD.

\section{Inflammation and structural remodelling}

Inflammation has been debated to play a fundamental role in small airways disease in COPD [58]. Chronic inflammatory response in small airways and lung parenchyma is mainly composed of macrophages, T-lymphocytes, neutrophils and eosinophils. A number of inflammatory mediators are involved comprising lipid mediators, inflammatory peptides, reactive oxygen and nitrogen species, chemokines, cytokines and growth factors. Many proteases are also involved and are responsible for the destruction of elastin fibres in lung parenchyma resulting in emphysema [58]. As a result, there are a variety of mediators, consistent with the clinical heterogeneity of COPD, but no preferentially identified target for therapy. 
The gold-standard tools for assessment of airway inflammation profile are invasive endobronchial wall biopsy and bronchial fluid lavage [59]. Non-invasive methods consist of analysing sputum or exhaled breath condensate $(\mathrm{EBC})$.

Sputum analysis has revealed a typical increase in neutrophils count in COPD patients. A variety of inflammation biomarkers are debated to play a role in the physiopathology of the disease, but collection of samples is limited by patients' ability to expectorate, tolerance and lack of repeatability of induced sputum procedures [60].

Cooling or freezing samples of exhaled air from the patient allows for EBC collection, which is further analysed biochemically [61]. This technique has the advantage of being easily repeatable and much better tolerated than induced sputum. The most promising EBC biomarkers studied in COPD are $\mathrm{pH}$, 8 -isoprostane, leukotriene B4 and hydrogen peroxide [62]. They have shown abnormal values at basal state $[63,64]$ and elevated levels during exacerbation $[65,66]$, except for $\mathrm{pH}$; acidification was found only in asthma exacerbations [67].

However, these measurements suffer from important interpatient variability and technical standard guidelines for sample collection have recently been updated in order to facilitate interpretation of therapeutic effects in the future [68].

The hallmark of chronic inflammatory airway disease is an important quantity of mucus, leading to chronic cough and disability. Small airways occlusion by mucus plugging has been found to be a predictive factor of mortality [69]. Other histopathological studies evidenced specific profiles of mucins MUC5B and MUC5AC in COPD bronchiolar lumen and epithelium [70]. More recently, results showed that MUC5B is the dominant secretory mucin expressed in distal airways [71].

Is this phenomenon resulting from failure of mucociliary clearance or oversecretion of mucins, or both? On the one hand, an increased mucus production has been recently found in induced sputum of COPD patients, suggesting a crucial role in chronic bronchitis [72]. Another noninvasive CT technique allowed quantification of mucus plugs in obstructive patients, which correlated with the level of airflow obstruction [73]

On the other hand, lung mucociliary clearance can be assessed with radiolabelled inhaled particles [74]. So far, this parameter has not been affected by interventions expected to improve COPD disability such as aerobic training [75] or inhaled tiotropium [76]. The mucociliary clearance was improved after smoking cessation at nasal level only [77].

Another consequence of chronic inflammation is structural remodelling of the bronchiolar walls. Such changes are studied with histological analysis of bronchial endoscopic biopsies. Thickness of the epithelium is increased in GOLD 3-4 COPD patients [78], attributed to squamous metaplasia [79] and hyperplasia of airway basal cells [80]. The squamous metaplasia has been shown to be correlated to the intensity of tobacco smoking [81] and has an extension associated with the level of obstruction [38].

In addition, peribronchiolar fibrosis develops as extracellular amorphous material composed of collagen [82]. It contributes to the bronchiolar wall thickening by means of growth factors [83].

Smooth muscle has been assessed, but does not seem to play an important role in COPD [84].

Other inflammation markers have been assessed in blood samples. Eosinophils seem to play a minor role in COPD, although their presence has been reported in proximal airways during viral-induced exacerbations [85]. Concerning blood eosinophils, contrasted results have been found. A study addressing severe exacerbations found a faster response to treatment and lower hospitalisation duration in patients having lower blood eosinophil counts [86]. In addition, blood eosinophil levels in a general population was associated with a 1.76-fold increase risk of severe exacerbations [87]. However, recent prospective analysis did not show pertinence of this parameter for rate of exacerbations nor for inhaled corticoid efficacy [88]. Furthermore, recent reports evidenced that blood eosinophil count does not reflect tissue eosinophil infiltration and that a higher level was not associated with worse outcomes [89].

Another promising blood marker is fibrocytes, key effector cells in fibrotic diseases, which have been recently suggested to play a role in obstructive diseases [90], but need further study.

Inflammatory infiltration observed in small airways wall thickening is related to smoking exposure, but is rather independent of smoking intensity and is classically self-perpetuating after smoking cessation. It has been proposed that inflammation in COPD small airways was related to autoimmune mechanisms triggered by smoke exposure [91]. This hypothesis has been explored more precisely in the case of emphysema. A murine model for emphysema has been obtained using endothelial cells antibodies [92]. Furthermore, chronic cigarette smoke exposure leads to the generation of pathogenic T-cells able to induce 
COPD in host mice [93]. LeE et al. [94] described antielastin autoantibodies in subjects with tobacco smoking-induced emphysema. More recently, chronic inflammation studies have demonstrated an increased level of B-cells and lymphoid follicles in correlation with disease severity. Autoantibodies produced by B-cells are present in COPD lungs and may contribute to injury. These findings represent a promising potential immunotherapeutic target to slow disease progression $[95,96]$.

Small airways consist of respiratory bronchioles containing specific bronchiolar cells known as club cells. They produce the club cell secretory protein (CCSP), also called CC16, which is the most abundant protein found in the airway surface fluid [97, 98]. As this protein may be involved in small airway homeostasis, it has been the subject of much research in recent years [99].

BERNARD et al. [100] reported that serum CC16 levels were significantly lower in COPD patients than in nonsmoker controls, but also in smokers as compared to nonsmokers [101]. Such results have been confirmed in the ECLIPSE cohort [102].

In murine models, CC16 deficiency increases smoke-induced lung pathologies by its effects on epithelial cells, leukocytes and fibroblasts. Emphysema-like lesions due to chronic inflammation have been found in CCSP-deficient mice [103]. Similarly, cigarette smoke (CS)-exposed CC16 ${ }^{-1-}$ mice had greater small airway fibrosis than CS-exposed wild-type mice [104]. Collectively, these studies suggest a protective role of CCSP in CS-induced oxidative stress [105, 106].

In clinical studies, reduced serum CC16 levels have been associated with accelerated decline in FEV1 over 9 years [107]. CC16 levels have been associated with chronic bronchitis and decline in lung function even before subjects develop COPD [108]. Low serum CC16 levels were prospectively associated with lower FEV1 in children, accelerated FEV1 decline in adults, and increased risk of stage 2 airflow limitation in the general adult population [109].

Accordingly, supplementation with recombinant CC16 in COPD may be a particularly interesting strategy.

Cigarette smoke extract exposure attenuates the inflammatory response linked to interleukin (IL)-8 and other markers of immune defence in COPD patients as compared to smokers without airflow obstruction [110]. This result suggests a deficient immune response specifically in COPD patients, triggered by cigarette smoke. Using IL-8 as a surrogate marker of COPD vulnerability, it was shown in vitro that the use of recombinant CC16 reduced mucus metaplasia and the release of IL-8 induced by CSE in airway epithelial cells from COPD patients $[111,112]$.

Initial in vivo results for recombinant CC16 delivery in infant respiratory distress syndrome indicate that a single dose can be delivered safely intratracheally, and that it reduces indicators of acute lung inflammation and injury [113].

However, the most attractive approach would be to develop orally available small molecules that boost CC16 expression by airway epithelial cells [99]. As a result, there is a theoretical background to propose that COPD patients having small airway-predominant disease are likely to respond to recombinant CC16 therapy.

A synthetic summary of these numerous inflammation-based processes is presented in table 3 .

\section{Pulmonary vascularisation}

COPD primarily impairs ventilation. However, the respiration process drastically involves gas exchange and thus pulmonary vasculature. As a result, potential vessel injuries may participate in COPD disability beyond bronchial obstruction.

Pioneering work from LiEBOw [114] reported loss of pulmonary capillaries in emphysema. Animal experiments with chronic smoke exposure have reproduced such pulmonary vascular changes [115], while imaging confirmed this feature [116].

Classically, areas of high alveolar ventilation/perfusion ratio $\left(V^{\prime} \mathrm{A} / Q^{\prime} \mathrm{A}\right)$ are observed in emphysematous patients. These regions have preserved ventilation and lowered perfusion, possibly due to capillary loss, microvascular obstruction or positive end-expiratory pressure linked to dynamic hyperinflation [117]. The multiple inert gas elimination technique confirmed that acute COPD exacerbations are linked to $V^{\prime} \mathrm{A} / Q^{\prime} \mathrm{A}$ mismatching $[117,118]$. In addition, pulmonary artery enlargement measured by CT was associated with severe COPD exacerbations [119]. These results highlight the fundamental role of pulmonary vasculature in COPD symptoms.

The effects of cigarette smoke on vascular endothelium is well known [120]. Basic science studies suggest that such deleterious effects also occur on the pulmonary vasculature [121]. Pulmonary vessels have the skill to adapt their calibre in order to match lung blood flow to ventilation, to adjust to high-altitude living and to protect lung capillaries from flooding due to increased precapillary pulmonary arterial pressure. 
TABLE 3 Summary of the reviewed inflammation-based processes involved in chronic obstructive pulmonary disease

\begin{tabular}{|c|c|c|c|}
\hline & Site & Components & Consequences \\
\hline $\begin{array}{l}\text { Mucus and inflammatory } \\
\text { exudates }\end{array}$ & Intraluminal airways & $\begin{array}{l}\text { Mucins } \\
\text { Inflammation mediators }\end{array}$ & $\begin{array}{l}\text { Chronic cough } \\
\text { Small airways obstruction }\end{array}$ \\
\hline Peribronchiolar fibrosis & Bronchiolar walls & Fibrosis & Structural wall thickening \\
\hline Smooth muscle & Bronchiolar walls & Increased size/tone & Structural wall thickening \\
\hline Eosinophils & Proximal airways and blood & Eosinophil cells & $\begin{array}{l}\text { Minor contribution, no } \\
\text { consensus }\end{array}$ \\
\hline Fibrocytes & Blood & Blood circulating cells & Fibrosis/repair process? \\
\hline Adaptative immunity & $\begin{array}{l}\text { Lung, extracellular matrix } \\
\text { and alveolar attachments }\end{array}$ & $\begin{array}{l}\text { B-cells, lymphoid follicles, } \\
\text { auto-antibodies }\end{array}$ & Emphysema \\
\hline Club cell secretory protein & Bronchiolar club cells & $\begin{array}{l}\text { Small airways homeostasis } \\
\text { protein }\end{array}$ & $\begin{array}{l}\text { Emphysema and small airways } \\
\text { fibrosis }\end{array}$ \\
\hline
\end{tabular}

\#: in contrast to structural remodelling, functional wall thickening refers to processes that do not directly affect histopathological structure.

Specific pulmonary artery endothelial dysfunction, that is, impairment of blood vessel calibre adaptation, was found after 3 months' smoke exposure and preceded the appearance of emphysema lesions in guinea-pigs [122]. Pulmonary endothelial dysfunction has been evidenced ex vivo in COPD lungs, through endothelium-dependent relaxation of pulmonary arteries [123]. Accordingly, endothelium-dependent pulmonary arteries relaxation in vitro was found lower in COPD versus smokers and nonsmokers [124]. Moreover, an inflammatory endothelium profile suggested potential involvement of an inflammatory process in the pathogenesis of pulmonary vascular abnormalities at early stage of COPD [125].

Systemic airway endothelial dysfunction has been investigated using albuterol responsiveness measured using the multiple inert gas technique. WANNER and MENDES [126] reported a blunted bronchial vascular response to albuterol, that is airway endothelial dysfunction, in asthma, COPD and smokers compared to healthy nonsmokers. Interestingly, a long-term (several weeks) treatment with inhaled corticosteroids improved albuterol responsiveness in both asthma and COPD patients, thereby identifying the airway endothelium as a potential therapeutic target in the treatment of airway disease [127, 128].

In healthy smokers, bronchial endothelial dysfunction was similarly assessed, but in combination with systemic extrapulmonary endothelial dysfunction measured by brachial arterial flow-mediated vasodilatation. An impairement of airway vascular endothelial function was found to precede systemic endothelial dysfunction [129].

As a result, studies show that predominant vascular changes in COPD and emphysema are endothelial and microvascular dysfunction [130]. They probably appear early in the disease and take part in its pathogenesis. Although toxic cigarette effects may occur at the beginning of the disease, hypoxia-induced vascular changes may also occur after disease evolution, leading to pulmonary hypertension and consequent heart disease.

An increased level of COPD severity was associated with a decreased heart size. Indeed, hyperinflation could play an important role regarding heart size and heart dysfunction in patients with COPD. Particularly, left ventricular diastolic filling is impaired in patients with static hyperinflation [131]. Another study found that emphysema and airflow obstruction were linearly related to reduction in left ventricular filling without changes in ejection fraction [132].

Accordingly, COPD patients were found to have reduced right ventricular volume in the MESA (Multi-Ethnic Study of Atherosclerosis) COPD cohort [133]. In addition, percentage emphysema was associated with smaller right ventricle volumes and lower mass, probably involving increased pulmonary vascular resistance [134].

CT studies showed that emphysema extent was correlated to blood vessel pruning (CSA $<5 \mathrm{~mm}^{2}$ ), thereby highlighting a pulmonary vascular phenotype $[22,135,136]$. This decreased proportion of small pulmonary vessels has also been linked with pulmonary hypertension [116] and clinical outcomes [137] in COPD patients. Interestingly, longitudinal follow-up of CSA $<5 \mathrm{~mm}^{2}$ may indicate once more that vessel pruning precedes emphysema evolution [138]. 
Traditional explanations for pulmonary hypertension in COPD are emphysema destruction leading to loss of vasculature and hypoxemia-induced vasoconstriction. However, tobacco-induced vascular injury possibly leads to a specific mechanism for pulmonary hypertension in COPD with a combined arterial disease (group 1) and hypoxia-induced vascular disease (group 3) [139]. Although this latter mechanism may not be present in non-hypoxaemic COPD patients, some of them develop pulmonary hypertension. Pathobiological features of the pulmonary vasculature suggest that pulmonary hypertension can occur with or without emphysematous lung tissue destruction and with or without loss of lung vessels. In COPD patients, vasculature damage and haemodynamic changes influence regional lung blood flow. The combination of vascular injury and shear stress may result in the formation of neointimal lesions [140] with proliferation of smooth muscle-like cells, leading to pulmonary hypertension.

Finally, there is compelling evidence for a pulmonary vascular disease in COPD patients, as illustrated schematically in figure 2. Interestingly, a subset of patients has been described recently as having a "pulmonary vascular phenotype", with a vascular disease expression exceeding the expected level in proportion to lung destruction [141].

Specific pulmonary hypertension therapy targeting pulmonary vascular endothelium may impair gas exchange by inhibiting hypoxic pulmonary vasoconstriction [142] and is currently lacking efficacy in COPD patients [141]

Vascular endothelial growth factor (VEGF) is a target of interest as it has fundamental role in vascular regulation. Indeed, impaired VEGF signalling causes emphysema in animal models [143] and some alterations in tissue VEGF expression have been observed in COPD patients. However, serum VEGF levels have not been associated with clinically significant outcomes in COPD [144].

Explorations of the vascular component in COPD rely on lung diffusing capacity and pulmonary vascular imaging.

Lung diffusing capacity is assessed in standard care with carbon monoxide uptake. It is classically decreased in emphysema [145]. Consequently, emphysema is usually characterised by low DLCO and chronic bronchitis by normal DLCO. DLCO technique is routinely used as a marker of alveolar-capillary membrane conductance. Recent research work found that smokers with normal spirometry but low DLCO

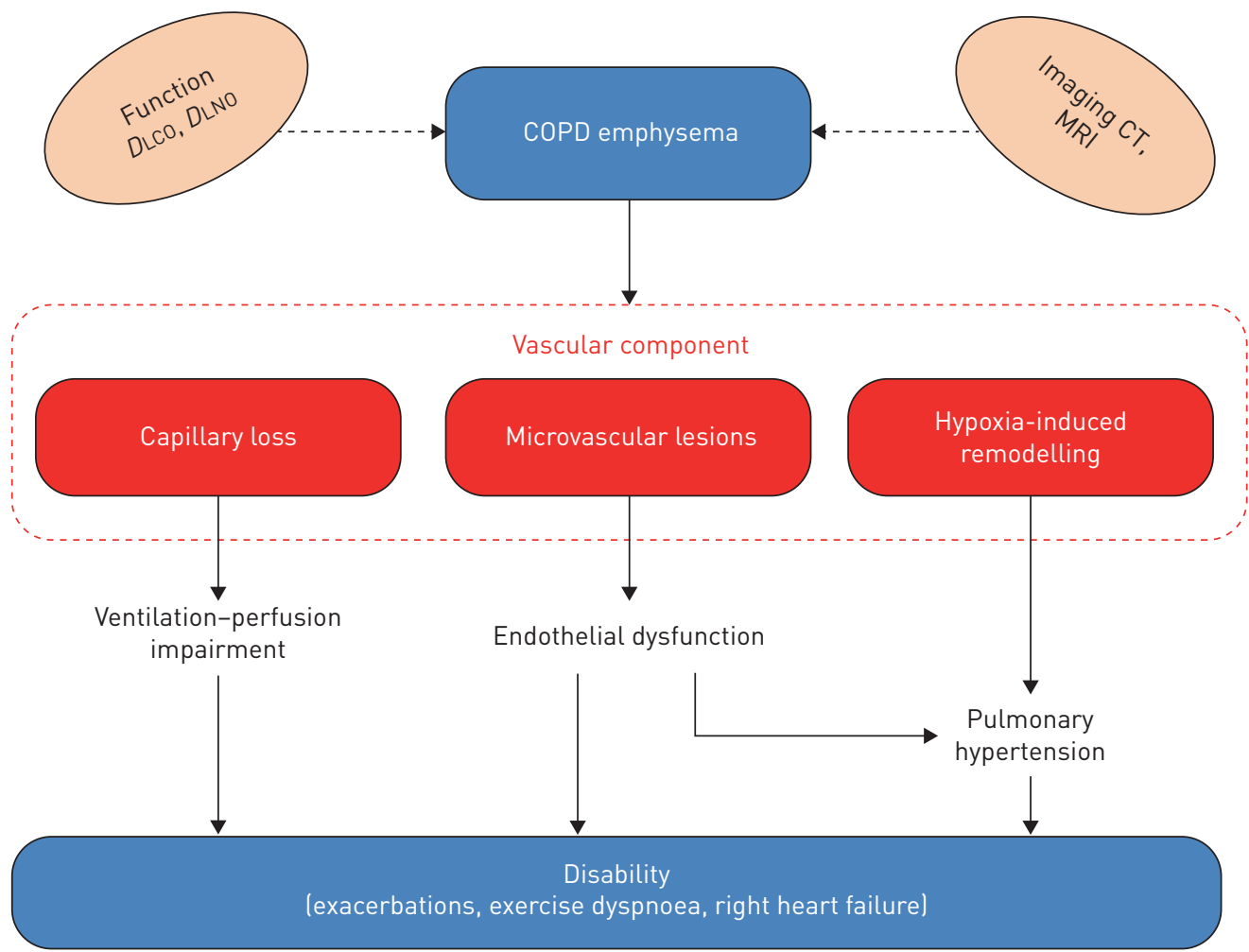

FIGURE 2 Schematic summary of the altered vascular component in emphysema. Capillary loss, microvascular lesions and hypoxia-induced remodelling play an important role in respiratory disability. DLco: diffusing capacity of the lung for carbon monoxide; DLNO: diffusing capacity of the lung for nitric oxide; COPD: chronic obstructive pulmonary disease; CT: computed tomography; MRI: magnetic resonance imaging. 
have significantly higher risk to develop airflow obstruction [146], supporting the existence of early vascular injury in COPD.

Additional measurement of diffusion capacity of the lung for nitric oxide has been proposed to separate the lung blood volume component from membrane diffusing capacity [147]. In principle, this tool may differentiate alveolocapillary diffusion alterations due to membrane disease with those due to microvascular disruption. It has been the subject of recent guidelines for standardisation of the test [148].

Echocardiography is routinely used to estimate pulmonary arterial pressure [149]. Novel CT tools, as described earlier, but also magnetic resonance imaging (MRI)-based pulmonary vascular blood flow assessment are promising tools being developed. Using contrast-enhanced MRI in the MESA COPD cohort, a 30\% reduction of pulmonary microvascular blood flow (PMBF) in mild COPD patients was shown compared to control subjects. This supports evidence for early microvascular damage in the disease. Findings suggest that reduced PMBF is a predominant feature of emphysematous COPD and less important in small airways disease and gas trapping [150].

\section{Conclusion}

In conclusion, COPD is a heterogeneous disease and more precise description of phenotypes should help to develop personalised treatments in the future. Owing to the failure of bronchial-obstruction-only description in patients' symptoms, specific non-obstructive phenotypes of patients such as "pulmonary vascular phenotype" [141] may represent valuable subjects for better understanding of respiratory disability.

Emerging tools addressing lung imaging such as quantitative CT have already brought great insight in COPD pathogenesis. Micro-CT and functional CT imaging of small airways or pulmonary vascular MRI may in the future bring new information. Combination of functional tests using FOT or nitrogen washout have provided useful information on small airways, and additional gas diffusion capacity could shed light on the pulmonary vascular component of the disease. Ongoing inflammation-based research provides promising biomarkers and innovative therapeutic strategies. Vascular endothelial dysfunction probably plays an important role in the progression of COPD symptoms and disability. Progression of the disease is an expanding topic and lung function trajectories from childhood to old age have been described recently as determinants of COPD [151]. Loss of pulmonary vessels or small airways identified in this disease also raises questions about their pre-existence at paediatric roots [152].

Conflict of interest: T. Capron has nothing to disclose. A. Bourdin reports personal fees from Novartis, Sanofi, Genentech and Chiesi Farma, and grants and personal fees from GSK, AstraZeneca and Boeringher Ingelheim, outside the submitted work. T. Perez reports personal fees from Novartis, Chiesi and Boehringer Ingelheim, and grants from Astra Zeneca, outside the submitted work. P. Chanez reports grants and personal fees from ALK, Almirall, Boehringer Ingelheim, GSK, AstraZeneca, Novartis, TEVA and Chiesi, and grants from AMU, outside the submitted work.

\section{References}

1 Fletcher C, Peto R. The natural history of chronic airflow obstruction. Br Med J 1977; 1: 1645-1648.

2 Barnes PJ, Celli BR. Systemic manifestations and comorbidities of COPD. Eur Respir J 2009; 33: 1165-1185.

3 Vestbo J, Hurd SS, Agustí AG, et al. Global strategy for the diagnosis, management, and prevention of chronic obstructive pulmonary disease: GOLD executive summary. Am J Respir Crit Care Med 2013; 187: 347-365.

4 Vogelmeier CF, Criner GJ, Martinez FJ, et al. Global strategy for the diagnosis, management, and prevention of chronic obstructive lung disease 2017 report. GOLD executive summary. Am J Respir Crit Care Med 2017; 195: 557-582.

5 Agusti A, Calverley PMA, Celli B, et al. Characterisation of COPD heterogeneity in the ECLIPSE cohort. Respir Res 2010; 11: 122 .

6 Lopez-Campos JL, Fernandez-Villar A, Calero-Acuña C, et al. Evaluation of the COPD Assessment Test and GOLD patient types: a cross-sectional analysis. Int J Chron Obstruct Pulmon Dis 2015; 10: 975-984.

7 Vestbo J, Edwards LD, Scanlon PD, et al. Changes in forced expiratory volume in 1 second over time in COPD. N Engl J Med 2011; 365: 1184-1192.

8 Wan ES, Hokanson JE, Murphy JR, et al. Clinical and radiographic predictors of GOLD-unclassified smokers in the COPDGene study. Am J Respir Crit Care Med 2011; 184: 57-63.

9 Wan ES, Castaldi PJ, Cho $\mathrm{MH}$, et al. Epidemiology, genetics, and subtyping of preserved ratio impaired spirometry (PRISm) in COPDGene. Respir Res 2014; 15: 89.

10 Pirozzi CS, Gu T, Quibrera PM, et al. Heterogeneous burden of lung disease in smokers with borderline airflow obstruction. Respir Res 2018; 19: 223.

11 Alcaide AB, Sanchez-Salcedo P, Bastarrika G, et al. Clinical features of smokers with radiological emphysema but without airway limitation. Chest 2017; 151: 358-365.

12 Woodruff PG, Barr RG, Bleecker E, et al. Clinical significance of symptoms in smokers with preserved pulmonary function. N Engl J Med 2016; 374: 1811-1821.

13 Regan EA, Lynch DA, Curran-Everett D, et al. Clinical and radiologic disease in smokers with normal spirometry. JAMA Intern Med 2015; 175: 1539-1549. 
Ranga V, Kleinerman J. Structure and function of small airways in health and disease. Arch Pathol Lab Med 1978; 102: 609-617.

Hogg JC, Macklem PT, Thurlbeck WM. Site and nature of airway obstruction in chronic obstructive lung disease. N Engl J Med 1968; 278: 1355-1360.

Macklem PT, Mead J. Resistance of central and peripheral airways measured by a retrograde catheter. J Appl Physiol 1967; 22: 395-401.

Yanai M, Sekizawa K, Ohrui T, et al. Site of airway obstruction in pulmonary disease: direct measurement of intrabronchial pressure. J Appl Physiol 1992; 72: 1016-1023.

Burgel P-R, Bourdin A, Chanez P, et al. Update on the roles of distal airways in COPD. Eur Respir Rev 2011; 20 $7-22$.

Mauad T, Silva LFF, Santos MA, et al. Abnormal alveolar attachments with decreased elastic fiber content in distal lung in fatal asthma. Am J Respir Crit Care Med 2004; 170: 857-862.

Burgel P-R. The role of small airways in obstructive airway diseases. Eur Respir Rev 2011; 20: 23-33.

Labaki WW, Martinez CH, Martinez FJ, et al. The role of chest computed tomography in the evaluation and management of the patient with chronic obstructive pulmonary disease. Am J Respir Crit Care Med 2017; 196: $1372-1379$.

Matsuoka S, Washko GR, Dransfield MT, et al. Quantitative CT measurement of cross-sectional area of small pulmonary vessel in COPD. Acad Radiol 2010; 17: 93-99.

Nakano Y, Muro S, Sakai H, et al. Computed tomographic measurements of airway dimensions and emphysema in smokers. Correlation with lung function. Am J Respir Crit Care Med 2000; 162: 1102-1108.

Martinez $\mathrm{CH}$, Chen Y-H, Westgate PM, et al. Relationship between quantitative CT metrics and health status and BODE in chronic obstructive pulmonary disease. Thorax 2012; 67: 399-406.

Mets OM, Schmidt M, Buckens CF, et al. Diagnosis of chronic obstructive pulmonary disease in lung cancer screening computed tomography scans: independent contribution of emphysema, air trapping and bronchial wall thickening. Respir Res 2013; 14: 59.

Han MK, Kazerooni EA, Lynch DA, et al. Chronic obstructive pulmonary disease exacerbations in the COPDGene study: associated radiologic phenotypes. Radiology 2011; 261: 274-282.

Lynch DA, Austin JHM, Hogg JC, et al. CT-definable subtypes of chronic obstructive pulmonary disease: a statement of the Fleischner Society. Radiology 2015; 277: 192-205.

Smith BM, Austin JHM, Newell JD, et al. Pulmonary emphysema subtypes on computed tomography: the MESA COPD study. Am J Med 2014; 127: 94-23.

Hogg JC, McDonough JE, Suzuki M. Small airway obstruction in COPD: new insights based on micro-CT imaging and MRI imaging. Chest 2013; 143: 1436-1443.

McDonough JE, Yuan R, Suzuki M, et al. Small-airway obstruction and emphysema in chronic obstructive pulmonary disease. N Engl J Med 2011; 365: 1567-1575.

Tanabe N, Vasilescu DM, McDonough JE, et al. Micro-computed tomography comparison of preterminal bronchioles in centrilobular and panlobular emphysema. Am J Respir Crit Care Med 2017; 195: 630-638.

Galbán CJ, Han MK, Boes JL, et al. Computed tomography-based biomarker provides unique signature for diagnosis of COPD phenotypes and disease progression. Nat Med 2012; 18: 1711-1715.

Bhatt SP, Soler X, Wang X, et al. Association between Functional Small Airway Disease and FEV1 decline in chronic obstructive pulmonary disease. Am J Respir Crit Care Med 2016; 194: 178-184.

Pompe E, Galbán CJ, Ross BD, et al. Parametric response mapping on chest computed tomography associates with clinical and functional parameters in chronic obstructive pulmonary disease. Respir Med 2017; 123: 48-55.

McFadden ER, Linden DA. A reduction in maximum mid-expiratory flow rate. A spirographic manifestation of small airway disease. Am J Med 1972; 52: 725-737.

Quanjer PH, Weiner DJ, Pretto JJ, et al. Measurement of FEF25-75\% and FEF75\% does not contribute to clinical decision making. Eur Respir J 2014; 43: 1051-1058.

Comroe JH, Fowler WS. Non-uniformity of alveolar gas in patients with pulmonary disease. J Clin Invest 1950; 29: 805-806.

Cosio M, Ghezzo H, Hogg JC, et al. The relations between structural changes in small airways and pulmonary-function tests. N Engl J Med 1978; 298: 1277-1281.

Verbanck S, Schuermans D, Van Muylem A, et al. Ventilation distribution during histamine provocation. J Appl Physiol 1997; 83: 1907-1916.

Verbanck S, Schuermans D, Paiva M, et al. Small airway function improvement after smoking cessation in smokers without airway obstruction. Am J Respir Crit Care Med 2006; 174: 853-857.

Brusasco V, Barisione G, Crimi E. Pulmonary physiology: future directions for lung function testing in COPD. Respirology 2015; 20: 209-218.

Goldman MD, Saadeh C, Ross D. Clinical applications of forced oscillation to assess peripheral airway function. Respir Physiol Neurobiol 2005; 148: 179-194.

Grimby G, Takishima T, Graham W, et al. Frequency dependence of flow resistance in patients with obstructive lung disease. J Clin Invest 1968; 47: 1455-1465.

Van Noord JA, Clément J, Van de Woestijne KP, et al. Total respiratory resistance and reactance in patients with asthma, chronic bronchitis, and emphysema. Am Rev Respir Dis 1991; 143: 922-927.

Dellacà RL, Santus P, Aliverti A, et al. Detection of expiratory flow limitation in COPD using the forced oscillation technique. Eur Respir J 2004; 23: 232-240.

Crim C, Celli B, Edwards LD, et al. Respiratory system impedance with impulse oscillometry in healthy and COPD subjects: ECLIPSE baseline results. Respir Med 2011; 105: 1069-1078.

Frantz S, Nihlén U, Dencker M, et al. Impulse oscillometry may be of value in detecting early manifestations of COPD. Respir Med 2012; 106: 1116-1123.

Timmins SC, Diba C, Farrow CE, et al. The relationship between airflow obstruction, emphysema extent, and small airways function in COPD. Chest 2012; 142: 312-319.

Mikamo M, Shirai T, Mori K, et al. Predictors of phase III slope of nitrogen single-breath washout in COPD. Respir Physiol Neurobiol 2013; 189: 42-46. 
Cui L, Ji X, Xie M, et al. Role of inspiratory capacity on dyspnea evaluation in COPD with or without emphysematous lesions: a pilot study. Int J Chron Obstruct Pulmon Dis 2017; 12: 2823-2830.

Casaburi R, Rennard SI. Exercise limitation in chronic obstructive pulmonary disease. The O'Donnell threshold. Am J Respir Crit Care Med 2015; 191: 873-875.

Dilektasli AG, Porszasz J, Casaburi R, et al. A novel spirometric measure identifies mild COPD unidentified by standard criteria. Chest 2016; 150: 1080-1090.

Gong S-G, Yang W-L, Liu J-M, et al. Change in pulmonary function in chronic obstructive pulmonary disease stage 0 patients. Int J Clin Exp Med 2015; 8: 21400-21406.

Boeck L, Gensmer A, Nyilas S, et al. Single-breath washout tests to assess small airway disease in COPD. Chest 2016; 150: 1091-1100.

Yamagami H, Tanaka A, Kishino $\mathrm{Y}$, et al. Association between respiratory impedance measured by forced oscillation technique and exacerbations in patients with COPD. Int J Chron Obstruct Pulmon Dis 2017; 13: 79-89.

Timmins SC, Diba C, Schoeffel RE, et al. Changes in oscillatory impedance and nitrogen washout with combination fluticasone/salmeterol therapy in COPD. Respir Med 2014; 108: 344-350.

Molino A, Simioli F, Stanziola AA, et al. Effects of combination therapy indacaterol/glycopyrronium versus tiotropium on moderate to severe COPD: evaluation of impulse oscillometry and exacerbation rate. Multidiscip Respir Med 2017; 12: 25.

Barnes PJ. Mediators of chronic obstructive pulmonary disease. Pharmacol Rev 2004; 56: 515-548.

Fabbri LM, Durham S, Holgate ST, et al. Assessment of airway inflammation: an overview. Eur Respir J Suppl 1998; 26: 6S-8S.

Cazzola M, Novelli G. Biomarkers in COPD. Pulm Pharmacol Ther 2010; 23: 493-500.

Horváth I, Hunt J, Barnes PJ. Exhaled breath condensate: methodological recommendations and unresolved questions. Eur Respir J 2005; 26: 523-548.

Borrill ZL, Roy K, Singh D. Exhaled breath condensate biomarkers in COPD. Eur Respir J 2008; 32: 472-486. Kostikas K, Papatheodorou G, Psathak
COPD. Chest 2003; 124: 1373-1380. Papaioannou AI, Loukides S, Minas M, et al. Exhaled breath condensate $\mathrm{pH}$ as a biomarker of COPD severity in ex-smokers. Respir Res 2011; 12: 67.

Biernacki WA, Kharitonov SA, Barnes PJ. Increased leukotriene B4 and 8-isoprostane in exhaled breath condensate of patients with exacerbations of COPD. Thorax 2003; 58: 294-298

Dekhuijzen PN, Aben KK, Dekker I, et al. Increased exhalation of hydrogen peroxide in patients with stable and unstable chronic obstructive pulmonary disease. Am J Respir Crit Care Med 1996; 154: 813-816.

Antus B, Barta I, Kullmann T, et al. Assessment of exhaled breath condensate $\mathrm{pH}$ in exacerbations of asthma and chronic obstructive pulmonary disease: a longitudinal study. Am J Respir Crit Care Med 2010; 182: 1492-1497.

Horváth I, Barnes PJ, Loukides S, et al. A European Respiratory Society technical standard: exhaled biomarkers in lung disease. Eur Respir J 2017; 49: 1600965.

Hogg JC, Chu FSF, Tan WC, et al. Survival after lung volume reduction in chronic obstructive pulmonary disease: insights from small airway pathology. Am J Respir Crit Care Med 2007; 176: 454-459.

Caramori G, Di Gregorio C, Carlstedt I, et al. Mucin expression in peripheral airways of patients with chronic obstructive pulmonary disease. Histopathology 2004; 45: 477-484.

Okuda K, Chen G, Subramani DB, et al. Localization of secretory mucins MUC5AC and MUC5B in normal/ healthy human airways. Am J Respir Crit Care Med 2018; 199: 715-727.

Kesimer M, Ford AA, Ceppe A, et al. Airway mucin concentration as a marker of chronic bronchitis. $N$ Engl Med 2017; 377: 911-922.

Dunican EM, Elicker BM, Gierada DS, et al. Mucus plugs in patients with asthma linked to eosinophilia and airflow obstruction. J Clin Invest 2018; 128: 997-1009. 1983; 127: 41-56.

MR, Ramos EMC, Kalva-Filho CA, et al. Effects of 12 weeks of aerobic training on autonomic modulation, mucociliary clearance, and aerobic parameters in patients with COPD. Int J Chron Obstruct Pulmon Dis 2015; 10: $2549-2557$.

Hasani A, Toms N, Agnew JE, et al. The effect of inhaled tiotropium bromide on lung mucociliary clearance in patients with COPD. Chest 2004; 125: 1726-1734.

Ito JT, Ramos D, Lima FF, et al. Nasal mucociliary clearance in subjects with COPD after smoking cessation. Respir Care 2015; 60: 399-405.

Hogg JC, Chu F, Utokaparch S, et al. The nature of small-airway obstruction in chronic obstructive pulmonary disease. $N$ Engl J Med 2004; 350: 2645-2653. interactions in COPD patients. J Clin Invest 2007; 117: 3551-3562. Care Med 2014; 190: 1355-1362.

Peters EJ, Morice R, Benner SE, et al. Squamous metaplasia of the bronchial mucosa and its relationship to smoking. Chest 1993; 103: 1429-1432.

Wright JL, Postma DS, Kerstjens HaM, et al. Airway remodelling in the smoke exposed guinea pig model. Inhal Toxicol 2007; 19: 915-923.

Churg A, Tai $\mathrm{H}$, Coulthard $\mathrm{T}$, et al. Cigarette smoke drives small airway remodelling by induction of growth factors in the airway wall. Am J Respir Crit Care Med 2006; 174: 1327-1334.

Corsico A, Milanese M, Baraldo S, et al. Small airway morphology and lung function in the transition from normality to chronic airway obstruction. J Appl Physiol 2003; 95: 441-447.

Papi A, Bellettato CM, Braccioni F, et al. Infections and airway inflammation in chronic obstructive pulmonary disease severe exacerbations. Am J Respir Crit Care Med 2006; 173: 1114-1121.

Serafino-Agrusa L, Scichilone N, Spatafora M, et al. Blood eosinophils and treatment response in hospitalized exacerbations of chronic obstructive pulmonary disease: a case-control study. Pulm Pharmacol Ther 2016; 37: 89-94. 
Vedel-Krogh S, Nielsen SF, Lange P, et al. Blood eosinophils and exacerbations in chronic obstructive pulmonary disease. The Copenhagen General Population Study. Am J Respir Crit Care Med 2016; 193: 965-974.

Roche N, Chapman KR, Vogelmeier CF, et al. Blood eosinophils and response to maintenance chronic obstructive pulmonary disease treatment. Data from the FLAME trial. Am J Respir Crit Care Med 2017; 195: 1189-1197.

Turato G, Semenzato U, Bazzan E, et al. Blood eosinophilia neither reflects tissue eosinophils nor worsens clinical outcomes in chronic obstructive pulmonary disease. Am J Respir Crit Care Med 2018; 197: 1216-1219.

Dupin I, Contin-Bordes C, Berger P. Fibrocytes in asthma and chronic obstructive pulmonary disease: variations on the same theme. Am J Respir Cell Mol Biol 2018; 58: 288-298.

Cosio MG, Saetta M, Agusti A. Immunologic aspects of chronic obstructive pulmonary disease. N Engl J Med 2009; 360: 2445-2454.

Taraseviciene-Stewart L, Scerbavicius R, Choe K-H, et al. An animal model of autoimmune emphysema. Am J Respir Crit Care Med 2005; 171: 734-742.

Motz GT, Eppert BL, Wesselkamper SC, et al. Chronic cigarette smoke exposure generates pathogenic T cells capable of driving COPD-like disease in Rag2 $2^{-1-}$ mice. Am J Respir Crit Care Med 2010; 181: 1223-1233.

Lee S-H, Goswami S, Grudo A, et al. Antielastin autoimmunity in tobacco smoking-induced emphysema. Nat Med 2007; 13: 567-569.

Polverino F, Seys LJM, Bracke KR, et al. B cells in chronic obstructive pulmonary disease: moving to center stage. Am J Physiol Lung Cell Mol Physiol 2016; 311: L687-L695.

Seys LJM, Verhamme FM, Schinwald A, et al. Role of B cell-activating factor in chronic obstructive pulmonary disease. Am J Respir Crit Care Med 2015; 192: 706-718.

Wong AP, Keating A, Waddell TK. Airway regeneration: the role of the Clara cell secretory protein and the cells that express it. Cytotherapy 2009; 11: 676-687.

Van Vyve T, Chanez P, Bernard A, et al. Protein content in bronchoalveolar lavage fluid of patients with asthma and control subjects. J Allergy Clin Immunol 1995; 95: 60-68.

Laucho-Contreras ME, Polverino F, Tesfaigzi Y, et al. Club cell protein 16 (CC16) augmentation: a potentia disease-modifying approach for chronic obstructive pulmonary disease (COPD). Expert Opin Ther Targets 2016; 20: 869-883.

Bernard A, Marchandise FX, Depelchin S, et al. Clara cell protein in serum and bronchoalveolar lavage. Eur Respir J 1992; 5: 1231-1238.

Bernard A, Roels H, Buchet JP, et al. Decrease of serum Clara cell protein in smokers. Lancet 1992; 339: 1620. Lomas DA, Silverman EK, Edwards LD, et al. Evaluation of serum CC-16 as a biomarker for COPD in the ECLIPSE cohort. Thorax 2008; 63: 1058-1063.

Matsumoto T, Fujita M, Hirano R, et al. Chronic Pseudomonas aeruginosa infection-induced chronic bronchitis and emphysematous changes in CCSP-deficient mice. Int J Chron Obstruct Pulmon Dis 2016; 11: 2321-2327.

Laucho-Contreras ME, Polverino F, Gupta K, et al. Protective role for club cell secretory protein-16 (CC16) in the development of COPD. Eur Respir J 2015; 45: 1544-1556.

Knabe L, Fort A, Chanez P, et al. Club cells and CC16: another "smoking gun"? (With potential bullets against COPD). Eur Respir J 2015; 45: 1519-1520.

Knabe L, Varilh J, Bergougnoux A, et al. CCSP G38A polymorphism environment interactions regulate CCSP levels differentially in COPD. Am J Physiol Lung Cell Mol Physiol 2016; 311: L696-L703.

Park HY, Churg A, Wright JL, et al. Club cell protein 16 and disease progression in chronic obstructive pulmonary disease. Am J Respir Crit Care Med 2013; 188: 1413-1419.

Petersen H, Leng S, Belinsky SA, et al. Low plasma CC16 levels in smokers are associated with a higher risk for chronic bronchitis. Eur Respir J 2015; 46: 1501-1503.

Guerra S, Halonen M, Vasquez MM, et al. Relation between circulating CC16 concentrations, lung function, and development of chronic obstructive pulmonary disease across the lifespan: a prospective study. Lancet Respir Med 2015; 3: 613-620.

0 Comer DM, Kidney JC, Ennis M, et al. Airway epithelial cell apoptosis and inflammation in COPD, smokers and nonsmokers. Eur Respir J 2013; 41: 1058-1067.

Gamez AS, Gras D, Petit A, et al. Supplementing defect in club cell secretory protein attenuates airway inflammation in COPD. Chest 2015; 147: 1467-1476.

inflammation. Eur Respir J 2014; 44: 1002-1010.

Levine CR, Gewolb IH, Allen K, et al. The safety, pharmacokinetics, and anti-inflammatory effects of intratracheal recombinant human Clara cell protein in premature infants with respiratory distress syndrome. Pediatr Res 2005; 58: 15-21.

Liebow AA. Pulmonary emphysema with special reference to vascular changes. Am Rev Respir Dis 1959; 80: 67-93.

Yamato H, Sun JP, Churg A, et al. Cigarette smoke-induced emphysema in guinea pigs is associated with diffusely decreased capillary density and capillary narrowing. Lab Investig 1996; 75: 211-219.

Matsuoka S, Washko GR, Yamashiro T, et al. Pulmonary hypertension and computed tomography measurement of small pulmonary vessels in severe emphysema. Am J Respir Crit Care Med 2010; 181: 218-225.

Wagner PD, Dantzker DR, Dueck R, et al. Ventilation-perfusion inequality in chronic obstructive pulmonary disease. J Clin Invest 1977; 59: 203-216.

Barberà JA, Roca J, Ferrer A, et al. Mechanisms of worsening gas exchange during acute exacerbations of chronic obstructive pulmonary disease. Eur Respir J 1997; 10: 1285-1291.

Wells JM, Washko GR, Han MK, et al. Pulmonary arterial enlargement and acute exacerbations of COPD. N Engl J Med 2012; 367: 913-921.

Leone A, Landini L. Vascular pathology from smoking: look at the microcirculation! Curr Vasc Pharmacol 2013 11: 524-530.

Ferrer E, Peinado VI, Castañeda J, et al. Effects of cigarette smoke and hypoxia on pulmonary circulation in the guinea pig. Eur Respir J 2011; 38: 617-627.

Ferrer E, Peinado VI, Díez M, et al. Effects of cigarette smoke on endothelial function of pulmonary arteries in the guinea pig. Respir Res 2009; 10: 76. 
Dinh-Xuan AT, Higenbottam TW, Clelland CA, et al. Impairment of endothelium-dependent pulmonary-artery relaxation in chronic obstructive lung disease. N Engl J Med 1991; 324: 1539-1547.

124 Peinado VI, Barbera JA, Ramirez J, et al. Endothelial dysfunction in pulmonary arteries of patients with mild COPD. Am J Physiol 1998; 274: 6 Pt. 1, L908-L913.

125 Peinado VI, Barberá JA, Abate P, et al. Inflammatory reaction in pulmonary muscular arteries of patients with mild chronic obstructive pulmonary disease. Am J Respir Crit Care Med 1999; 159: 1605-1611.

anner A, Mendes ES. Airway endothelial dysfunction in asthma and chronic obstructive pulmonary disease: a challenge for future research. Am J Respir Crit Care Med 2010; 182: 1344-1351.

127 Peinado VI, Pizarro S, Barberà JA. Pulmonary vascular involvement in COPD. Chest 2008; 134: 808-814.

128 Clarenbach CF, Senn O, Sievi NA, et al. Determinants of endothelial function in patients with COPD. Eur Respir J 2013; 42: 1194-1204

129 Mendes ES, Cancado JED, Rebolledo P, et al. Airway vascular endothelial function in healthy smokers without systemic endothelial dysfunction. Chest 2013; 143: 1733-1739.

130 Barr RG. The epidemiology of vascular dysfunction relating to chronic obstructive pulmonary disease and emphysema. Proc Am Thorac Soc 2011; 8: 522-527.

131 Watz H, Waschki B, Meyer T, et al. Decreasing cardiac chamber sizes and associated heart dysfunction in COPD: role of hyperinflation. Chest 2010; 138: 32-38.

132 Barr RG, Bluemke DA, Ahmed FS, et al. Percent emphysema, airflow obstruction, and impaired left ventricular filling. N Engl J Med 2010; 362: 217-227.

133 Kawut SM, Poor HD, Parikh MA, et al. Cor pulmonale parvus in chronic obstructive pulmonary disease and emphysema: the MESA COPD study. J Am Coll Cardiol 2014; 64: 2000-2009.

134 Grau M, Barr RG, Lima JA, et al. Percent emphysema and right ventricular structure and function: the Multi-Ethnic Study of Atherosclerosis-Lung and Multi-Ethnic Study of Atherosclerosis-Right Ventricle Studies. Chest 2013; 144: 136-144.

135 Coste F, Dournes G, Dromer C, et al. CT evaluation of small pulmonary vessels area in patients with COPD with severe pulmonary hypertension. Thorax 2016; 71: 830-837.

136 Coste F, Benlala I, Dournes G, et al. Quantitative CT assessment of bronchial and vascular alterations in severe precapillary pulmonary hypertension. Int J Chron Obstruct Pulmon Dis 2019; 14: 381-389.

137 Washko GR, Nardelli P, Ash SY, et al. Arterial vascular pruning, right ventricular size and clinical outcomes in COPD. Am J Respir Crit Care Med 2019; in press https://doi.org/10.1164/rccm.201811-2063OC.

138 Saruya S, Matsuoka S, Yamashiro T, et al. Quantitative CT measurements of small pulmonary vessels in chronic obstructive pulmonary disease: do they change on follow-up scans? Clin Physiol Funct Imaging 2016; 36: 211-217.

139 Voelkel NF, Gomez-Arroyo J, Mizuno S. COPD/emphysema: the vascular story. Pulm Circ 2011; 1: 320-326.

140 Sakao S, Voelkel NF, Tatsumi K. The vascular bed in COPD: pulmonary hypertension and pulmonary vascular alterations. Eur Respir Rev 2014; 23: 350-355.

141 Kovacs G, Agusti A, Barberà JA, et al. Pulmonary vascular involvement in chronic obstructive pulmonary disease. Is there a pulmonary vascular phenotype? Am J Respir Crit Care Med 2018; 198: 1000-1011.

142 Blanco I, Piccari L, Barberà JA. Pulmonary vasculature in COPD: the silent component. Respirology 2016; 21: 984-994.

143 Kasahara Y, Tuder RM, Taraseviciene-Stewart L, et al. Inhibition of VEGF receptors causes lung cell apoptosis and emphysema. J Clin Invest 2000; 106: 1311-1319.

144 Boeck L, Mandal J, Costa L, et al. Longitudinal Measurement of Serum Vascular Endothelial Growth Factor in Patients with Chronic Obstructive Pulmonary Disease. Respiration 2015; 90: 97-104.

145 Bates DV. The uptake of carbon monoxide in health and in emphysema. Clin Sci 1952; 11: 21-32.

146 Harvey B-G, Strulovici-Barel Y, Kaner RJ, et al. Risk of COPD with obstruction in active smokers with normal spirometry and reduced diffusion capacity. Eur Respir J 2015; 46: 1589-1597.

147 Guenard H, Varene N, Vaida P. Determination of lung capillary blood volume and membrane diffusing capacity in man by the measurements of NO and CO transfer. Respir Physiol 1987; 70: 113-120.

148 Zavorsky GS, Hsia CCW, Hughes JMB, et al. Standardisation and application of the single-breath determination of nitric oxide uptake in the lung. Eur Respir J 2017; 49: 1600962.

149 Galiè N, Humbert M, Vachiery J-L, et al. 2015 ESC/ERS Guidelines for the diagnosis and treatment of pulmonary hypertension: The Joint Task Force for the Diagnosis and Treatment of Pulmonary Hypertension of the European Society of Cardiology (ESC) and the European Respiratory Society (ERS). Eur Respir J 2015; 46: 903-975.

150 Hueper K, Vogel-Claussen J, Parikh MA, et al. Pulmonary microvascular blood flow in mild chronic obstructive pulmonary disease and emphysema. The MESA COPD study. Am J Respir Crit Care Med 2015; 192: 570-580.

151 Belgrave DCM, Granell R, Turner SW, et al. Lung function trajectories from pre-school age to adulthood and their associations with early life factors: a retrospective analysis of three population-based birth cohort studies. Lancet Respir Med 2018; 6: 526-534.

152 Martinez FJ, Han MK, Allinson JP, et al. At the root: defining and halting progression of early chronic obstructive pulmonary disease. Am J Respir Crit Care Med 2018; 197: 1540-1551. 